DOI: $10.17805 / g g z .2019 .3 .4$

\title{
Осознанная многодетность как социальное явление
}

А. А. Ибрагимова, С. Н. Испулова

Магнитогорский государственный технический университет им. Г. И. Носова

Настоящая статья посвящена изучению осознанного многодетного родительства как социального явления. Рассмотрены структура родительства, а также сущность материнства и отцовства как ключевых компонентов данной структуры. Выделены факторы формирования осознанной многодетности, такие как потребность родителей в самореализации, индивидуальная направленность личности на рождение и воспитание детей, низкая степень выраженности у индивидов мотивов ограничения числа детей и рачиональное планирование большего их числа, связанное с наличием достаточного уровня материального благополучия и поддержки со стороны близких родственников и членов семьи.

Ключевые слова: многодетность; родительство; осознанное родительство; эффективное родительство; осознанная многодетность

\section{Conscious Multi-Child Parenting as a Social Phenomenon}

A. A. Ibragimova, S. N. Ispulova

Nosov Magnitogorsk State Technical University

This article focuses on the study of responsible multi-child parenthood as a social phenomenon. The authors consider the structure of parenthood, as well as the essence of motherhood and fatherhood as key components of this structure. We outline reasons for a conscious wish to have a large number of children, such as the need for self-realization, individual openness to having children, a small amount of motivations for limiting the number of children and a rational planning to have a large family, associated with a sufficient level of material well-being and support from close relatives and family members.

Keywords: multi-child parenting; parenthood; conscious parenting; effective parenting; responsible multi-child parenting

\section{ВВЕДЕНИЕ}

Осознанное выполнение родительской роли, выражающейся в качественном воспитании, определяет состояние психологического здоровья лич- 
ности подрастающего поколения, института семьи и общества в целом. Происходящая в последние годы трансформация семьи как основного социального института привела к распространению негативных явлений, таких как малодетность и связанное с ней увеличение числа однодетных семей, уход от традиционного распределения ролей и ответственности в системе семейнобрачных отношений, феминизация, ослабление отцовской роли и снижение стабильности семьи.

Распространение последствий трансформации российской семьи наряду с высоким уровнем смертности населения в свою очередь способствовали возникновению неблагоприятной демографической ситуации, выражающейся в устойчивом сокращении численности населения России. В связи с этим решение обозначенных проблем видится в распространении многодетных семей, характеризующихся сознательным рождением детей и осознанным выполнением основных социальных функций, связанных с их воспитанием и уходом.

Предметом данного исследования является многодетность как осознанное явление.

Цель исследования состоит в попытке определить механизмы формирования осознанной многодетности на основе анализа научной литературы.

\section{СУЩНОСТЬ ОСОЗНАННОГО РОДИТЕЛЬСТВА}

Проблеме изучения феномена родительства в отечественной и зарубежной науке посвящено достаточно много работ. К числу наиболее значимых среди них необходимо отнести исследования А. И. Антонова, А. Бертина, В. А. Борисова, Н. А. Гительсона, И. В. Добрякова, В. Н. Дружинина, М. О. Ермихиной, Н. П. Коваленко, И. С. Кона, Р. В. Овчаровой, П. А. Сорокина, Г. Г. Филипповой. Однако, хотя проблемы, связанные с феноменом родительства, относительно неплохо изучены, его сущность до сих пор полностью не раскрыта.

С появлением детей в семье супруги сознательно или неосознанно приобретают новый статус родителей. Однако необходимо отметить, что биологическая способность быть родителем не всегда соответствует сформированной психологической готовности к выполнению родительских ролей, формирующейся под влиянием различных факторов и выражающейся в осознании себя родителем и способах реализации родительской роли. С точки зрения В. Н. Дружинина (Дружинин, 1996), родительство выражается в родительской ответственности, определяющей поведение родителей и имеющей дуальную природу: ответственность перед обществом и перед самим собой в вопросах духовного и физического развития детей. 
Родительство определяется как сложное социальное явление, выступающее обязательным условием обеспечения воспроизводства будущего поколения, а также значимым компонентом личностной сферы человека. Также данное понятие рассматривается и как социокультурный феномен, отражающий ход развития человеческой культуры и накопленного социального опыта и являющийся своеобразным индикатором состояния общества (Лущенко, Некрасов, 2014: 124).

В понимании Р. В. Овчаровой родительство представляет собой сложное социальное образование, выступающее компонентом структуры общества, который выполняет специфические функции в тесном взаимодействии с остальными структурными компонентами общественной системы. Кроме этого, структура родительства, как подчеркивает исследователь, включает совокупность субъектов, разные по характеру отношения, события, процессы и социальную практику, формирующуюся и поддерживающуюся обществом, а также возобновляющуюся в процессе жизнедеятельности индивидов, интегрирующихся в общество (Овчарова, 2006: 43).

Родительство играет важную роль в жизни детей, на протяжении жизни которых родители продолжают оставаться значимыми фигурами. При этом феномен родительства включает материнство и отцовство, каждое из которых обладает своими специфическими функциями и социальным, экономическим и правовым статусами. В свою очередь материнство выступает своеобразным гарантом стабильности и репродукции общества, находящимся между природой и культурой, что определяет его уникальность и ценность. Суть исторически возникшего в моногамной семье отцовства, одного из основных проявлений мужской идентичности, состоит «в готовности мужчины взять на себя ответственность за содержание и воспитание своих детей» (Лущенко, Некрасов, 2014: 126).

Основу родительства, по мнению Е. В. Заливухиной, составляют аспекты, связанные с родительскими чувствами, любовью и привязанностью к детям, специфическими ролями и нормативными предписаниями культуры, стилем воспитания и отношения к детям. В то же время, как утверждает исследователь, содержательную сторону родительства составляет мотивация деторождения, а специфика современного родительства рассматривается с точки зрения смены исторических типов детности, в соответствии с которыми первым типом является многодетность, характеризующаяся индивидуальным выбором супругов. При этом решение о рождении нескольких детей принимается в соответствии с жизненными планами, целями и установками (Заливухина, 2011: 375-376). 
В работах Т. Аренделла при исследовании феномена современного родительства выделяются два основных тренда, в рамках которых родительство рассматривается как место родителя в современном обществе и как практика воспитания детей, в том числе включающий опыт воспитания и переживание собственной успешности как родителя - родительскую самоэффективность (Поливанова, 2015: 2-3). Формирование осознанного родительства, по представлению Е. И. Захаровой, осуществляется задолго до начала реализации роли родителей. В частности, это формирование происходит в процессе наблюдения за родителями и старшим поколением, что позволяет подготовиться к реализации собственных родительских ролей (Захарова, 2012).

В последнее время начинают появляться и развиваться такие модели осознанного родительства как:

1. естественное родительство, начинающееся с естественных родов и продолжающееся в тесном телесном контакте матери с ребенком (совместный сон детей и родителей, долгое грудное вскармливание);

2. альфа-родительство, предполагающее акцент на отношениях с детьми, обеспечивающее правильное воспитание;

3. интенсивное родительство, включающее различные практики воспитания детей, максимально способствующие их развитию через соответствующие формы и виды стимуляции (Ньюфелд, Матэ, 2012);

4. эффективное родительство, представляющее собой систему взаимоотношений между родителями и детьми, способствующую полноценному развитию личности последних и эмоциональному благополучия обоих. Структуру системы эффективного родительства составляют:

- подсистема отношений ребенка, включающая отношение к самому себе, отношения с родителями и адекватность поведения в обществе;

- подсистема отношений родителей, состоящая из отношения к самим себе как родителям, отношения к ребенку и избранного стиля воспитания (Нестерова, 2003).

Ключевым критерием эффективного родительства выступает личностная зрелость, которая в сочетании с родительской любовью и направленностью на самоактуализацию личности образует рациональный контроль.

\section{ФАКТОРЫ ФОРМИРОВАНИЯ \\ СОЗНАТЕЛЬНОЙ МНОГОДЕТНОСТИ}

Социологами выделяются следующие факторы, обуславливающие сознательную многодетность: 
- рациональное планирование большего числа детей, напрямую связанное с наличием хороших жилищных условий, высоким уровнем материального дохода и качеством отношений внутри семьи;

- наличие поддержки со стороны старших членов семьи и близких родственников;

- многодетность как результат «социального заражения» вследствие общения с другими многодетными семьями (Симанкова, 2019: Электронный pecypc).

Не менее значимым фактором, детерминирующим многодетность, является ценность здоровья, занимающая в сознании будущих родителей одно из лидирующих мест в системе других ценностей. Необходимо отметить, что рассматриваемый фактор определяется как ключевой, так как состояние здоровья оказывает непосредственное влияние на трудоспособность и связанное с ней материальное положение индивидов, а значит и на возможность и способность воспитывать и растить детей (Бодров, Боярова, 2016: 85).

Исследования А. Синельникова свидетельствуют о влиянии религиозных установок на формирование мотивов рождения детей и репродуктивное поведение индивидов. Однако, как отмечает автор, данное влияние в большей степени характерно для формирования мотивов рождения первого и второго ребенка в семье, в то время как многодетность по-прежнему остается в меньшинстве (Синельников, 2010: Электронный ресурс).

Преобладающим компонентом «в родительской мотивации является репродуктивный мотив, содержание которого определяется ценностносмысловыми установками самих родителей» (Ананьева, 2015: 101). В содержании репродуктивной мотивации многодетных родителей исследователями выделяются следующие параметры:

- любовь к детям, отражающая индивидуальную направленность личности на рождение и воспитание детей — чадолюбие (В. В. Бойко);

- сильная потребность в наличии собственных детей (А. И. Антонов);

- реализация мотива поддержания социального статуса взрослого, выражающегося в достижении социальной идентичности личности, в том числе продлении своего рода;

- обеспечение условий, при которых дети могли бы общаться и гармонично развиваться;

- «низкая выраженность мотивов ограничения числа детей (Е. С. Кузьмин, Е. С. Семенов, Г. Е. Цуладзе)» (там же).

В продолжение рассмотрения мотивов репродуктивного поведения, представляющего собой систему действий и отношений, ведущих к рождению или отказу от рождения детей, нельзя не отметить потребность в детях, 
определяющуюся как психологическое свойство личности индивидов, выражающееся в их стремлении обзаводиться принятым и одобряемым обществом количеством детей. Согласно мнению О. В. Устиновой и И. В. Пивоваровой, ослабление социальных мотивов в репродуктивном поведении индивидов обусловлено тем, что рождение третьего и последующих детей часто принимается вопреки, господствующим в современном обществе, нормам малодетности (Устинова, Пивоварова, 2015).

Интересна точка зрения В. А. Борисова и А. И. Антонова (Борисов, Антонов, 1990) о том, что ранее причиной формирования установки на многодетность являлась экономическая мотивация деторождения, заключающаяся в экономической полезности большего количества детей. М. С. Мацковский (Мацковский, 1989: 23) и П. А. Сорокин (Сорокин, 1999) отмечают, что на современном этапе развития института семьи экономический фактор рождаемости утратил свое значение, произошла его замена на социальнопсихологическое значение для родителей.

Многодетность, с точки зрения Г. А. Банных и его соавторов, определяется как сложный социокультурный и экономический феномен, основу которого составляет запланированное репродуктивное поведение, в том числе потребности индивидов, исходящие из культурно-нравственных, национальных и религиозных стереотипов и норм (Банных и др., 2019). Следовательно, осознанную многодетность следует рассматривать как запланированную многодетность.

\section{ЗАКЛЮЧЕНИЕ}

Подводя итоги нашего краткого обзора представленных подходов к рассмотрению осознанного родительства и многодетности, можно констатировать следующее: родительство представляет собой сложный многогранный феномен, основу структуры которого составляют ценности, родительские установки, ожидания, родительские позиции, чувства, ответственность, опыт и стиль воспитания детей. Выявлено, что родительство выражается на двух уровнях: субъективно-личностном и индивидуальном, которые одновременно являются этапами его формирования. Основными факторами, формирующими осознанное многодетное родительство, выступают:

- потребность родителей в самореализации;

- индивидуальная направленность человека на рождение и воспитание детей;

- отсутствие у индивидов каких-либо существенных оснований для ограничения числа детей и рациональное планирование большего их числа 
при достаточном уровне материальной обеспеченности и наличии близких родственников и членов семьи, готовых оказывать помощь.

При этом с увеличением количества детей в семье увеличивается и родительский опыт, являющийся неотьемлемой составляющей общей структуры родительства и складывающийся из совокупности опыта отца и матери. В соответствии с этим можно сделать вывод, что в семьях с тремя и более детьми факторы формирования установок на многодетность определяют родительскую опытность и повышение стремления стимулировать развитие детей. Следует отметить, что современный институт родительства претерпевает существенные изменения. В новых социально-экономических условиях ценность родительства для индивидов, выражающаяся в детоцентричности, конкурирует с другими ценностями, в частности с успешной профессиональной деятельностью и карьерой. В данной ситуации решение о рождении большего числа детей становится осознанным выбором индивидов.

\section{СПИСОК ЛИТЕРАТУРЫ}

Ананьева, Н. Н. (2015) Субкультура многодетной семьи в современном обществе // Вестник славянских культур. № 3 (37). С. 99-104.

Банных, Г. А. и др. (2019) Феномен многодетности в России: социологический анализ изменений / Г. А. Банных, Е. В. Зайцева, С. Н. Костина, А. И. Кузьмин [Электронный ресурс] // Вопросы управления. № 1. С. 22-36. URL: http://vestnik.uapa.ru/ru/issue/2019/01/03/ [архивировано в WaybackMachine] (дата обращения: 22.06.2019). DOI: 10.22394/2304-3369-2019-1-22-36

Бодров, А. В., Боярова, Е. А. (2016) Образ многодетной семьи в зеркале общественного мнения // Вестник Саратовского государственного социально-экономического университета. № 5 (64). С. 84-89.

Борисов, В. А., Антонов, А. И. (1990) Кризис семьи и пути его преодоления : науч. докл. Ин-т социологии АН СССР. Сектор социал. пробл. семьи. М. : ИС. 36 с.

Дружинин, В. Н. (1996) Психология семьи. М. : КСП. 156, [2] с.

Заливухина, Е. В. (2011) Малодетность и бездетность в контексте современного родительства // Вестник Санкт-Петербургского университета. Серия 12: Психология. Социология. Педагогика. Вып. 4. С. 375-381.

Захарова, Е. И. (2012) Представление о характере социальной роли, как средство ориентировки в ее исполнении // Культурно-историческая психология. № 4. С. $38-41$.

Лущенко, Э. М., Некрасов, С. И. (2014) К вопросу о понятии «родительство» и его сущности // Ученые записки Орловского государственного университета. № 2 (58). С. 124-127. 
Мацковский, М. С. (1989) Социология семьи: проблемы теории, методологии и методики / отв. ред. Г. С. Батыгин. М. : Наука. 112, [4] с.

Нестерова, Е. А. (2003) Личностная зрелость в аспекте родительства // Психолого-педагогические проблемы этической психологии : мат. Межрегиональной науч.-практ. конф. : в 2 ч. Шадринск : Шадринский филиал Моск. гос. открыт. пед. ун-та им. М. А. Шолохова. Ч. II. С. 114-120.

Ньюфелд, Г., Матэ, Г. (2012) Не упускайте своих детей: почему родители должны быть важнее, чем ровесники. Изд. 2-е, испр. М. : Ресурс. 384 с.

Овчарова, Р. В. (2006) Родительство как психологический феномен. М. : Моск. психолого-социальный ин-т. 496 с.

Поливанова, К. Н. (2015) Современное родительство как предмет исследования // Психологическая наука и образование. Т. 7. № 3. С. 1-11. DOI: $\underline{10.17759 / \text { psyedu. } 2015070301}$

Симанкова, Е. (2019) Многодетностью можно «заразиться» [Электронный ресурс] // Милосердие.Ru. 4 февраля. URL: https://www.miloserdie.ru/ article/mnogodetnostyu-mozhno-zarazitsya/ [архивировано в WaybackMachine] (дата обращения: 22.06.2019).

Синельников, А. (2010) Семейная жизнь и религиозность [Электронный ресурс] // Demographia.ru. 1 февраля. URL: http://demographia.ru/articles _N/index.html?idArt=247 [архивировано в WaybackMachine] (дата обращения: 24.06.2019).

Сорокин, П. А. (1999) Преступление и кара, подвиг и награда: социологический этюд об основных формах общественного поведения и морали : К 110-й годовщине со дня рождения / подгот. В. В. Сапов. СПб. : Изд-во Русского христианского гуманит. ин-та. 446, [1] с.

Устинова, О. В., Пивоварова, И. В. (2015) Мотивы многодетности у современных россиян // Современные проблемы науки и образования. № 1-1. C. 1411 .

Дата поступления: 29.06.2019 г.

\section{REFERENCES}

Ananieva, N. N. (2015) Subkul'tura mnogodetnoi sem'i v sovremennom obshchestve [Subculture of large families in modern society]. Vestnik slavianskikh kul'tur, no. 3 (37), pp. 99-104. (In Russ.).

Bannykh, G. A. et al. (2019) Fenomen mnogodetnosti v Rossii: sotsiologicheskii analiz izmenenii [The phenomenon of large families in Russia: A sociological analysis of changes] / G. A. Bannykh, E. V. Zaitseva, S. N. Kostina and A. I. Kuzmin. Voprosy upravleniia, no. 1, pp. 22-36. [online] Available at: http:// 
vestnik.uapa.ru/ru/issue/2019/01/03/ [archived in WaybackMachine] (accessed: 22.06.2019). (In Russ.). DOI: 10.22394/2304-3369-2019-1-22-36

Bodrov, A. V. and Boyarova, E. A. (2016) Obraz mnogodetnoi sem'i v zerkale obshchestvennogo mneniia [The image of a large family in the mirror of public opinion]. Vestnik Saratovskogo gosudarstvennogo sotsial'no-ekonomicheskogo universiteta, no. 5 (64), pp. 84-89. (In Russ.).

Borisov, V. A. and Antonov, A. I. (1990) Krizis sem'i i puti ego preodoleniia [The crisis of the family and ways of its solution] : A scientific report. Institute of Sociology, Academy of Sciences of the USSR. Department of Family Social Issues. Moscow : IS Publ. 36 p. (In Russ.).

Druzhinin, V. N. (1996) Psikhologiia sem'i [Psychology of the family]. Moscow : KSP Publ. 156, [2] p. (In Russ.).

Zalivukhina, E. V. (2011) Malodetnost' i bezdetnost' v kontekste sovremennogo roditel'stva [Small families and childlessness in the context of modern parenthood]. Vestnik Sankt-Peterburgskogo universiteta. Seriia 12: Psikhologiia. Sotsiologiia. Pedagogika, issue 4, pp. 375-381. (In Russ.).

Zakharova, E. I. (2012) Predstavlenie o kharaktere sotsial'noi roli, kak sredstvo orientirovki $\mathrm{v}$ ee ispolnenii [Individual notions of social role characteristics as means of orientation in its implementation]. Kul'turno-istoricheskaia psikhologiia, no. 4, pp. 38-41. (In Russ.).

Lushchenko, E. M. and Nekrasov, S. I. (2014) K voprosu o poniatii «roditel'stvo» $\mathrm{i}$ ego sushchnosti [On the notion of parenthood and its essence]. Uchenye zapiski Orlovskogo gosudarstvennogo universiteta, no. 2 (58), pp. 124127. (In Russ.).

Matskovskii, M. S. (1989) Sotsiologiia sem'i: problemy teorii, metodologii i metodiki [Sociology of the family: Issues of the theory, methodology and methods] / ed. by G. S. Batygin. Moscow : Nauka Publ. 112, [4] p. (In Russ.).

Nesterova, E. A. (2003) Lichnostnaia zrelost' v aspekte roditel'stva [Personal maternity in the aspect of parenthood]. In: Psikhologo-pedagogicheskie problemy eticheskoi psikhologii [Psychological and pedagogical issues of ethical psychology] : Proceedings of the International research-to-practice conference : in 2 pts. Shadrinsk : Shadrinsk Branch of Sholokhov Moscow State Open Pedagogical University Publ. Pt. 2. Pp. 114-120. (In Russ.).

Neufeld, G. and Maté, G. (2012) Ne upuskaite svoikh detei: pochemu roditeli dolzhny byt' vazhnee, chem rovesniki [Hold on to your kids: Why parents need to matter more than peers]. 2nd edn, revised. Moscow : Resurs Publ. 384 p. (In Russ.). 
Ovcharova, R. V. (2006) Roditel'stvo kak psikhologicheskii fenomen [Parenthood as a psychological phenomenon]. Moscow : Moscow Psychological and Social Institute Publ. 496 p. (In Russ.).

Polivanova, K. N. (2015) Sovremennoe roditel'stvo kak predmet issledovaniia [Contemporary parenting and parenthood as research domains]. Psikhologicheskaia nauka i obrazovanie, vol. 7, no. 3, pp. 1-11. (In Russ.). DOI: 10.17759/ psyedu.2015070301

Simankova, E. (2019) Mnogodetnost'iu mozhno «zarazit'sia» [It is possible to become "infected" with possession of many children]. Miloserdie.Ru, February 4. [online] Available at: https://www.miloserdie.ru/article/mnogodetnostyumozhno-zarazitsya/ [archived in WaybackMachine] (accessed 22.06.2019). (In Russ.).

Sinelnikov, A. (2010) Semeinaia zhizn' i religioznost' [Family life and religiousness]. Demographia.ru, February 1. [online] Available at: http://demographia.ru/articles_N/index.html?idArt=247 [archived in WaybackMachine] (accessed 24.06.2019). (In Russ.).

Sorokin, P. A. (1999) Prestuplenie i kara, podvig i nagrada: sotsiologicheskii etiud ob osnovnykh formakh obshchestvennogo povedeniia $i$ morali [Crime and punishment, service and reward: A sociological essay on the main forms of social behavior and morals] : To the 110th anniversary of the birth / prepared by V. V. Sapov. St. Petersburg : Russian Christian Institute for the Humanities Publ. 446, [1] p. (In Russ.).

Ustinova, O. V. and Pivovarova, I. V. (2015) Motivy mnogodetnosti u sovremennykh rossiian [Motivations for having many children in contemporary Russians]. Sovremennye problemy nauki i obrazovaniia, no. 1-1, p. 1411. (In Russ.).

Submission date: 29.06 .2019$.

Ибрагимова Альбина Ахметовна - магистрант ФГБОУ ВО «Магнитогорский государственный технический университет им. Г. И. Носова», член РООМСЧО «Многодетство». Адрес: 455048, Россия, г. Магнитогорск, ул. Рабочая, д. 24. Тел.: +7 (912) 806-50-68. Эл. адрес: aalbinaa@ mail.ru

Испулова Светлана Николаевна - кандидат педагогических наук, доцент, доцент кафедры социальной работы и психолого-педагогического образования ФГБОУ ВО «Магнитогорский государственный технический университет им. Г. И. Носова». Адрес: 455026, Россия, г. Магнитогорск, ул. Советская, д. 119а, кв. 12. Тел.: +7 (912) 791-06-90. Эл. адрес: $\underline{\text { sispulova@ @ail.ru }}$ 
Ibragimova Albina Akhmetovna, master's degree student, G. I. Nosov Magnitogorsk State Technical University; member of the Regional Public Organization for Large Families in Chelyabinsk Oblast "Mnogodetstvo". Postal address: 24 Rabochaya St., 455048 Magnitogorsk, Russian Federation. Tel.: +7 (912) 806-5068. E-mail: aalbinaa@ mail.ru

Ispulova Svetlana Nikolaevna, Candidate of Pedagogy, Associate Professor, Department of Social Work, Psychological and Pedagogical Education, G. I. Nosov Magnitogorsk State Technical University. Postal address: Apt. 12, 119a Sovetskaya St., 455026 Magnitogorsk, Russian Federation. Tel.: +7 (912) 806-50-68. E-mail: sispulova@ mail.ru

Для циитирования:

Ибрагимова А. А., Испулова С. Н. Осознанная многодетность как социальное явление [Электронный ресурс] // Горизонты гуманитарного знания. 2019. № 3. C. 52-62. URL: http://journals.mosgu.ru/ggz/article/view/1044 (дата обращения: дд.мм.гггг). DOI: 10.17805/ggz.2019.3.4 